\title{
Laparoscopic guided mini-laparotomy. A novel technique for the management of benign large ovarian cysts: An interventional study
}

\author{
Mohamed Shaltout ${ }^{1}$, Ahmed Maged ${ }^{1}$, Sherif Sameh Zaki², Rana Abdella ${ }^{2}$, Mona Sediek$^{2}$, \\ Sherif Dahab², Rasha Elkomy², and Moutaz Elsherbini ${ }^{2}$ \\ ${ }^{1}$ Kasr Aini medical school \\ ${ }^{2}$ Cairo University Kasr Alainy Faculty of Medicine
}

November 3, 2020

\begin{abstract}
Objective to evaluate the efficiency and safety of a novel technique to keep benefits of laparoscopic management in women with large ovarian benign cysts without affection of the ovarian reserve Design: An interventional study Setting: Kasr Alainy medical school, Cairo university hospital Population: 112 women with large benign ovarian cyst candidate for ovarian cystectomy. Methods: The technique started with laparoscopy followed by guided cyst aspiration followed by exteriorization of the ovary through minilaprotomy and completion of cystectomy through microsurgical technique. Main Outcome Measures: The primary outcome was ipsilateral recurrence of the cyst. Other outcomes included ovarian reserve assessment and postoperative pain. Results: The number of women with recurrence in the ipsilateral ovary after 12, 18 and 24 months were $5(4.5 \%), 16(14.3 \%), 20$ $(17.85 \%)$ respectively. Assessment of ovarian reserve revealed a significant decrease in the level of serum AMH (2.82 \pm 0.44 vs. $2.50 \pm 0.42)$ and a significant increase in AFC (3.5 \pm 1.7 vs. $4.9 \pm 1.3)$ after our novel technique in the surgical treatment of ovarian cysts $(\mathrm{P}$-value $<0.001$ ). The operative time was $50 \pm 7$ and $62 \pm 7$ minutes in unilateral and bilateral cysts respectively. Conclusions: Laparoscopic guided minilaparotomy is a safe and effective technique for the management of large benign ovarian cysts with minimal recurrence rate, ovarian reserve affection, and adhesions.
\end{abstract}

\section{Hosted file}

Laparoscopic guided minilaparotomy.pdf available at https://authorea.com/users/372707/ articles/490641-laparoscopic-guided-mini-laparotomy-a-novel-technique-for-the-

management-of-benign-large-ovarian-cysts-an-interventional-study

\section{Hosted file}

Final Tables.pdf available at https://authorea.com/users/372707/articles/490641-laparoscopicguided-mini-laparotomy-a-novel-technique-for-the-management-of-benign-large-ovariancysts-an-interventional-study

\section{Hosted file}

Final Figures.pdf available at https://authorea.com/users/372707/articles/490641laparoscopic-guided-mini-laparotomy-a-novel-technique-for-the-management-of-benignlarge-ovarian-cysts-an-interventional-study 